\title{
Comportamento Ingestivo de Vacas Jersey Confinadas durante a Fase Inicial da Lactação 1
}

\section{Cintia Oliveira da Costa ${ }^{2}$, Vivian Fischer ${ }^{3}$, Marco Antônio Monks Vetromilla ${ }^{4}$, Claiton Baes Moreno ${ }^{5}$, Everson Xavier Ferreira ${ }^{6}$}

\begin{abstract}
RESUMO - Este trabalho foi desenvolvido com o objetivo de caracterizar o comportamento ingestivo de vacas da raça Jersey durante duas épocas do ano (estações fria e quente) e aos 30, 60 e 90 dias pós-parto. Os tempos diários gastos com ingestão, ruminação e descanso foram estimados a partir de observações visuais realizadas por um único observador bem treinado. Os registros das atividades comportamentais foram realizados a intervalos de 10 minutos, durante 24 horas por dia, cinco dias por período, totalizando 30 dias de observações. Os animais foram observados individualmente. Os tempos médios de ingestão e ruminação foram maiores na estação quente, comparados à estação fria e aos 30 dias pós-parto comparados aos 90 dias pós-parto, e associados com os efeitos positivos de temperatura, fotoperíodo e teor de fibra da silagem. O peso vivo decresceu até 30 dias pós-parto, apresentando recuperação aos 90 dias pós-parto. A produção de leite apresentou interação significativa entre época e período, com menor produção de leite aos 60 dias pós-parto em relação aos 30 e 90 dias pós-parto, principalmente na estação quente, fato parcialmente atribuído às mudanças na composição química da silagem. Concluiu-se que as vacas leiteiras modificaram seu comportamento ingestivo para se adaptarem às mudanças nutricionais, ambientais (efeito de época) e anatômicas e fisiológicas (efeito do número de dias após o parto).
\end{abstract}

Palavras-chave: descanso, ingestão, peso vivo, produção de leite, ruminação

\section{Ingestive Behavior of Jersey Cows in Free Stall at the Beginning of Lactation}

\begin{abstract}
This trial aimed to characterize the ingestive behavior of Jersey dairy cows during cool and warm seasons, and at 30, 60 and 90 days post-partum. Daily time spent eating, ruminating and idling was estimated through visual observations recorded by a well trained observer. Records were made intermittently, using 10 minutes interval during 24 hours, five days per period, totalizing 30 days of observations. Ingestive behavior was recorded for each individual animal. Daily eating and rumination times were larger at warm season compared to the cool one and at 30 days post-partum compared to 90 days post-partum, being associated with positive effects of temperature, photoperiod and fiber content of silage. Live weight decreased from parturition until 30 days post-partum and recovered by 90 days post-partum. Milk production showed a significant interaction effect among season and period, presenting smaller values at 60 than at 30 or 90 days post-partum, specially at warm season, what might be partially related to changes in the silage chemical composition. It is concluded that dairy cows changed ingestive behavior to adapt themselves to different nutritional, environmental (season effect) and anatomical, physiological conditions (effect of number of days after parturition)
\end{abstract}

Key Words: eating, idling, live weight, milk production, rumination

\section{Introdução}

O desempenho animal é determinado pelo consumo de nutrientes, sua digestibilidade e metabolismo. $\mathrm{O}$ consumo de alimentos, por sua vez, pode ser influenciado por fatores ligados aos alimentos, como palatabilidade, textura, aparência visual e fatores ligados aos animais, como estado emocional, interações e aprendizado (Mertens, 1994). O controle do consumo de alimentos está diretamente relacionado ao comportamento ingestivo (Chase et al., 1976). O consumo diário de alimentos compreende o número de refeições diárias, a sua duração e a taxa de ingestão. A vaca pode regular seu consumo diário de matéria seca (Dado \& Allen, 1994; Grant \& Albright, 1995) por meio do ajuste do número diário de refeições e do seu tamanho (duração x taxa de ingestão).

A redução do tamanho das partículas dos alimentos ingeridos é um pré-requisito para adequada digestão microbiana e do animal hospedeiro, que ocorre

1 Trabalho de mestrado do primeiro autor.

2 Médico veterinário, MS, Produção animal PPGZ-UFPEL. E.mail: cintoaocosta@bol.com.br

${ }^{3}$ Professor Adjunto do Departamento de Zootecnia- UFPEL. Caixa postal 354 - UFPEL - FAEM - DZ - Pelotas, RS. CEP: $96001-970$.

E.mail: vfried@portoweb.com.br

4 Pesquisador aposentado EMBRAPA - CPACT.

5 Bolsista de Iniciação científica da FAPERGS.

${ }^{6}$ Bolsista de Iniciação científica do CNPq. 
principalmente por intermédio da mastigação durante a ingestão e ruminação e, em menor grau, através da ação dos microrganismos ruminais (Beauchemin \& Buchanan-Smith, 1989). Dessa forma, o comportamento ingestivo pode influenciar a digestão dos alimentos e a sua taxa de passagem pelo trato gastrintestinal dos ruminantes. Porém, os animais podem alterar seu comportamento ingestivo, modificando um ou mais dos seus componentes para superar condições limitantes ao consumo e obter a quantidade de nutrientes necessária (Fischer, 1996).

A adequação do manejo produtivo e reprodutivo de vacas leiteiras pressupõe a compreensão das variações na ingestão de matéria seca, peso corporal e produção de leite (Gottschall, 1999). Durante a fase inicial da lactação (zero a 100 dias pós-parto), a vaca leiteira passa por transformações anatômicas, fisiológicas e endócrinas, que modificam seu metabolismo e contribuem para uma reduzida capacidade de consumo de matéria seca (Janssen, 1994; Grant \& Albright, 1995).

Podem-se identificar três períodos distintos na fase inicial de lactação. O primeiro, que compreende os 30 primeiros dias pós-parto, quando se verifica o pico de lactação, aliado à capacidade de consumo sub-ótima e à mobilização de reservas corporais para a produção leiteira, e, frequientemente, perda de condição corporal. $\mathrm{O}$ balanço energético negativo observado ocorre devido ao aporte insuficiente de nutrientes necessários à lactação pela dieta, mediado pela limitação da capacidade de consumo. Aos 60 dias pós parto, um período intermediário, a produção leiteira começa a diminuir, na ordem de $2,5 \%$ por semana, enquanto o consumo voluntário aumenta gradativamente. Por fim, o terceiro período situa-se aos 90 dias pós parto, posterior ao pico de consumo de MS (normalmente atingido entre 10 e 12 semanas após o parto), em que a produção leiteira continua a decrescer gradativamente (Janssen, 1994; NRC, 2001).

As modificações que ocorrem na capacidade de consumo durante a fase inicial da lactação podem alterar o comportamento ingestivo destes animais. A compreensão dos fenômenos envolvidos no comportamento ingestivo, pode contribuir para adequar o manejo nutricional de vacas de média à alta produção leiteira, na fase inicial de lactação, minimizando os efeitos prejudiciais do balanço energético negativo. $\mathrm{O}$ objetivo deste experimento foi caracterizar o comportamento ingestivo de vacas Jersey confinadas, em duas épocas do ano (estações fria e quente), e em três fases da lactação (em média aos 30, 60 e 90 dias após o parto) e verificar a relação existente entre os aspectos comportamentais e a produção leiteira.

\section{Material e Métodos}

Este experimento foi desenvolvido no sistema intensivo de pecuária leiteira na Estação Experimental de Terras Baixas, da EMBRAPA - CPACT, no município de Pelotas, RS.

O experimento foi conduzido de agosto de 1998 a janeiro de 1999 e constituiu-se de duas épocas com três períodos cada. As observações relativas à estação fria foram feitas nos meses de agosto, setembro e outubro de 1998. As observações relativas à estação quente ocorreram em novembro e dezembro de 1998 e janeiro de 1999.

Os animais observados foram mantidos em lotes com aproximadamente 20 animais, em condições de confinamento total, num sistema de estabulação livre (free stall). Na estação fria, foram observadas oito vacas Jersey com peso vivo médio de $393 \pm 51 \mathrm{~kg}$ e produção média diária de 12,9 $\pm 2,6$ litros de leite. $\mathrm{Na}$ estação quente, utilizaram-se seis vacas Jersey com peso vivo médio de $365 \pm 24 \mathrm{~kg}$ e produção média diária de 14,1 $\pm 2,5$ L. Utilizou-se ordenha mecânica, duas vezes por dia, às $8 \mathrm{~h}$ e às $17 \mathrm{~h}$, em uma sala de ordenha do tipo espinha de peixe.

Os animais receberam silagem de milho à vontade, 2 a 3 vezes/dia (às 9 h e 14 h e, às vezes, às 19 h) mais concentrado, nas quantidades por animal de $2 \mathrm{~kg}$ de após cada ordenha e mais $2 \mathrm{~kg}$ na primeira hora da tarde. Os alimentos foram colocados em cochos coletivos para todo o lote, onde primeiro se ofertou a silagem e por cima desta foi distribuída a mistura concentrada.

O concentrado foi composto, em média, por $45 \%$ de milho moído, $30 \%$ de farelo de soja, $15 \%$ de soja em grão moída, $7 \%$ de farelo de trigo, $1 \%$ de fosfato bicálcico, $1 \%$ de calcário calcítico e $1 \%$ de sal mineral. Amostras compostas dos alimentos foram analisadas, no Laboratório de Nutrição Animal, da Faculdade de Agronomia, UFPEL, para determinação de matéria seca (MS), matéria mineral, compostos nitrogenados $(\mathrm{N})$ (método Kjedahl), extrato etéreo e fibra bruta (FB) (AOAC, 1982). As determinações de cálcio e fósforo foram realizadas em espectrofotômetro de absorção atômica, conforme Tedesco et al. (1995) e Silva (1990), respectivamente. Os resultados são apresentados na Tabela 1.

Em cada período, os animais foram observados visualmente durante cinco dias alternados, começando 
Tabela 1 - Composição químico-bromatológica da silagem de milho (SM) e do concentrado (C) nos seis períodos de avaliação (\% da MS)

Table 1 - Chemical composition of corn silage (CS) and concentrate (C) at six measurement periods (\% of dry matter)

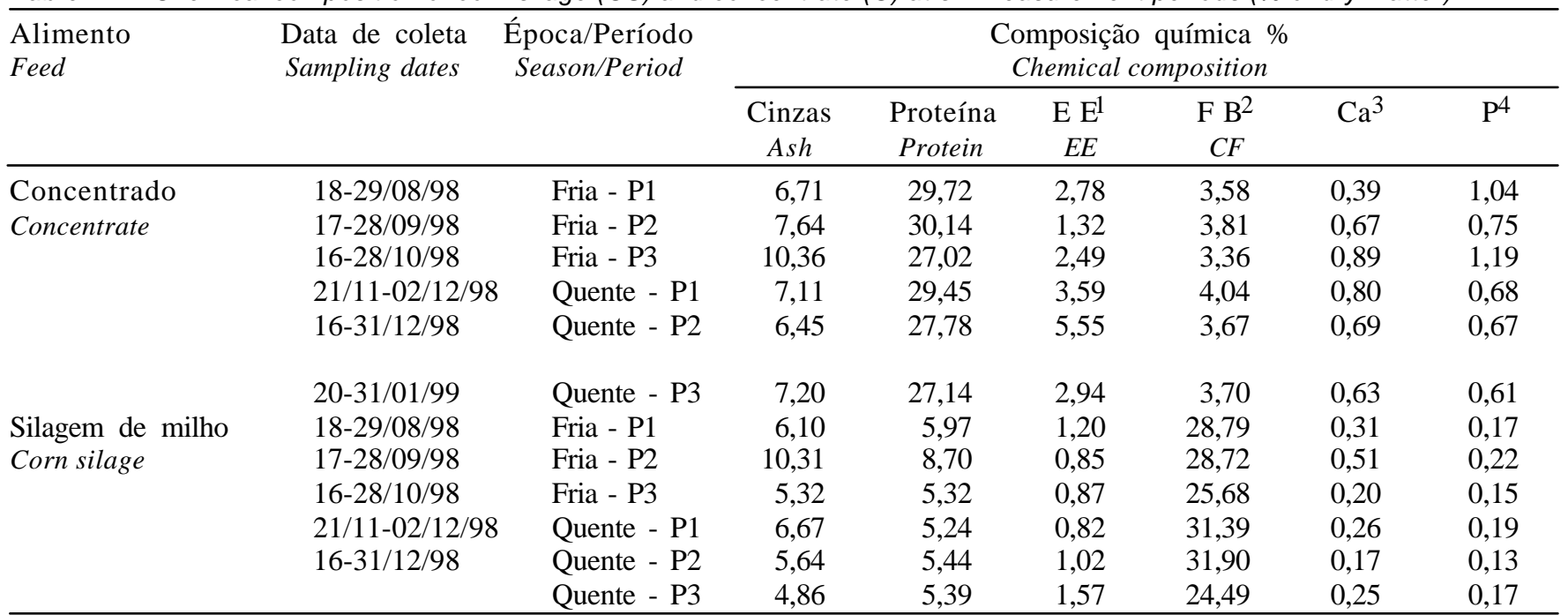

1 Extrato etéreo (ether extract).

${ }^{2}$ Fibra bruta (crude fiber).

${ }^{3}$ Cálcio (calcium)

${ }^{4}$ Fósforo (phosphorus).

às $11 \mathrm{~h}$ da manhã de um dia e terminando às $11 \mathrm{~h}$ da manhã do dia seguinte, durante 24 horas. O tempo total diário das atividades foi estimado a partir dos registros realizados para cada animal em intervalos de 10 minutos. O comportamento foi classificado em quatro atividades mutuamente excludentes: ingestão, ruminação, descanso (tempo despendido sem movimento mandibular) e outras atividades. Os animais foram pesados no primeiro e no último dia de cada período. A produção leiteira diária individual foi anotada em todos os dias de observação, em cada período. Os dados meteorológicos estão apresentados na Tabela 2.

$\mathrm{Na}$ análise estatística, foi feita a comparação entre épocas e entre períodos, utilizando-se um delineamento completamente casualizado, com medidas repetidas sobre os mesmos animais dentro de duas épocas, em que as fontes de variação foram época, período e a interação época $\mathrm{x}$ período.

$\mathrm{O}$ modelo matemático adotado foi:

$Y_{i j}=U+E_{i}+P_{j}+E_{i j}+E_{i j k}$, em que:

$\mathrm{Y}_{\mathrm{ij}}=$ observação realizada na iésima época e no jésimo período;

$\mathrm{U}=$ média geral do experimento;

$E_{i}=$ efeito de época: quente e fria $(n=2)$;

$\mathrm{P}_{\mathrm{j}}=$ efeito de período: três em cada época $(\mathrm{n}=3)$;

$\mathrm{EP}_{\mathrm{ij}}=$ efeito da interação entre período e época;

$\mathrm{E}_{\mathrm{ijk}}=$ erro aleatório
Tabela 2 - Dados climatológicos médios registrados nas estações fria e quente

Table 2 - Mean values of climatological data recorded on cool and warm seasons

\begin{tabular}{|c|c|c|c|}
\hline \multirow[t]{2}{*}{$\begin{array}{l}\text { Variável } \\
\text { Variable }\end{array}$} & \multicolumn{2}{|c|}{$\begin{array}{l}\text { Época } \\
\text { Season }\end{array}$} & \multirow[b]{2}{*}{$\begin{array}{l}\text { Valor } \mathrm{P} \\
P \text { value }\end{array}$} \\
\hline & $\begin{array}{l}\text { Fria } \\
\text { Cool }\end{array}$ & $\begin{array}{l}\text { Quente } \\
\text { Warm }\end{array}$ & \\
\hline $\begin{array}{l}\text { Temperatura mínima }\left({ }^{\circ} \mathrm{C}\right) \\
\text { Minimum temperature }\left({ }^{\circ} \mathrm{C}\right)\end{array}$ & 13,27 & 18,09 & 0,043 \\
\hline $\begin{array}{l}\text { Temperatura máxima }\left({ }^{\circ} \mathrm{C}\right) \\
\text { Maximum temperature }\left({ }^{\circ} \mathrm{C}\right)\end{array}$ & 20,31 & 27,11 & 0,071 \\
\hline $\begin{array}{l}\text { Temperatura média }\left({ }^{\circ} \mathrm{C}\right) \\
\text { Mean temperature }\left({ }^{\circ} \mathrm{C}\right)\end{array}$ & 16,42 & 21,79 & 0,044 \\
\hline $\begin{array}{l}\text { Umidade relativa }(\%) \\
\text { Relative humidity }(\%)\end{array}$ & 80,93 & 76,25 & 0,458 \\
\hline $\begin{array}{l}\text { Velocidade do vento }(\mathrm{km} / \mathrm{h}) \\
\text { Wind velocity }(\mathrm{km} / \mathrm{h})\end{array}$ & 4,07 & 4,87 & 0,358 \\
\hline $\begin{array}{l}\text { Fotoperíodo (minutos) } \\
\text { Photoperiod (minutes) }\end{array}$ & 725,33 & 837,07 & 0,031 \\
\hline
\end{tabular}

Foi utilizado o teste de Wilks Lambda para avaliar os efeitos de época, período e época x período e o nível de significância adotado para rejeitar a hipótese de nulidade foi de 0,05 .

As variáveis consideradas foram os tempos diários de ingestão, ruminação e descanso, produção leiteira e peso vivo médio. Na comparação das médias dos períodos utilizaram-se contrastes (teste F). 


\section{Resultados e Discussão}

Os resultados obtidos dos efeitos de época e período sobre o tempo diário gasto nas atividades de ingestão, ruminação e descanso, o peso vivo e a produção leiteira encontram-se na Tabela 3 .

Houve efeito de época sobre as três atividades do repertório comportamental. Os tempos médios de ingestão e ruminação foram maiores na estação quente (376 e $583 \mathrm{~min} /$ dia, respectivamente) em relação à estação fria (326 e $525 \mathrm{~min} /$ dia, respectivamente, $\mathrm{P}=0,0257$ e $\mathrm{P}=0,0152$ ). Contrariamente, o tempo diário médio de descanso reduziu-se na estação quente em comparação com a estação fria $(478$ x $580 \mathrm{~min} /$ dia, $\mathrm{P}=0,0021)$, pois as três atividades comportamentais observadas neste trabalho são complementares e mutuamente excludentes. Estas observações estão de acordo com Deswysen et al. (1993) e Fischer (1996), que verificaram a competição entre os três tipos de atividades considerados (ingestão x ruminação x descanso) na alocação do tempo, pelo animal.

As causas das diferenças de comportamento ingestivo entre as duas épocas podem ser atribuídas em grande parte às condições climáticas distintas nas duas épocas de avaliação. Pois, ocorreram diferenças significativas de temperatura entre as duas épocas (Tabela 2), e, na estação quente, foram observados maiores valores de temperatura mínima $\left(13,27^{\circ} \mathrm{C}\right.$ $\left.\mathrm{X} 18,09^{\circ} \mathrm{C}, \mathrm{P}=0,043\right)$, média $\left(16,42^{\circ} \mathrm{C} \times 21,79^{\circ} \mathrm{C}\right.$, $\mathrm{P}=0,044)$ e máxima $\left(20,31^{\circ} \mathrm{C} \mathrm{X} 27,11^{\circ} \mathrm{C}, \mathrm{P}=0,071\right)$.

Em animais submetidos às temperaturas elevadas, o consumo e a produção de leite tendem a diminuir (Albright, 1993). Em condições de frio, o consumo total de alimentos e a taxa de consumo são freqüentemente aumentados, o que pode provocar uma diminuição do tempo total de ingestão. $\mathrm{O}$ aumento do consumo e das contrações musculares e da necessidade em gerar calor, para manter a temperatura corporal, leva a ao incremento do peristaltismo do trato gastrintestinal (Young, 1987), o que aumenta a velocidade de passagem da digesta, podendo reduzir os tempos de ingestão e de ruminação. Outros autores verificaram que vacas, submetidas às temperaturas baixas a moderadas, apresentaram maior tempo de ingestão à medida que a temperatura média se elevou (Prescott et al., 1994). Deswysen et al. (1993) encontraram que animais que apresentaram maiores taxas de consumo, despendiam menos tempo por dia ruminando e ingerindo que os outros animais com menor consumo voluntário. Os animais com maior nível de consumo apresentaram maior taxa de passagem da digesta e partículas que escaparam pelo orifício retículoomasal com maior diâmetro (Deswysen et al., 1987).

As temperaturas ambientes observadas no presente estudo, durante a estação fria, encontram-se entre os limites de conforto térmico, de 4,44 a $23,88^{\circ} \mathrm{C}$ (Fraser, 1973), indicando que os animais não estavam estressados do ponto de vista térmico. Porém, as temperaturas baixas observadas nesta época podem ter exercido um efeito positivo sobre a taxa de ingestão e/ou passagem dos alimentos, reduzindo os tempos totais das atividades de ingestão e ruminação. Esta hipótese encontra sustentação nos resultados da análise de correlação.

As temperaturas máxima e média foram positivamente correlacionadas com o tempo de ruminação (respectivamente $\mathrm{r}=0,31, \mathrm{P}=0,0441 ; \mathrm{r}=0,31, \mathrm{P}=0,0460$ ) e negativamente relacionada com o tempo de descanso ( $\mathrm{r}=-0,33, \mathrm{P}=0,0340 ; \mathrm{r}=-0,33, \mathrm{P}=0,0304)$.

Entretanto, a temperatura normalmente exerce uma influência mais direta sobre os padrões comportamentais durante um ciclo de 24 horas do que sobre os tempos totais diários destas atividades (Ray \& Roubicek, 1971). Hoffman \& Self (1973) também não observaram efeito da temperatura sobre o comportamento ingestivo de novilhos confinados.

Além das diferenças de temperatura, constataram-se diferenças quanto ao fotoperíodo entre as duas épocas. $\mathrm{O}$ fotoperíodo foi superior na estação quente em relação à estação fria $(725,33$ X 837,07 min, $\mathrm{P}=0,031$ ). Diversos autores registraram efeito estimulador de fotoperíodos crescentes sobre a ocorrência da atividade de ingestão em gado leiteiro (Zinn et al., 1983) e sobre o consumo voluntário em ovinos (Fischer, 1996). A análise de correlação mostrou que o fotoperíodo foi positivamente relacionado aos tempos de ingestão $(\mathrm{r}=0,32, \mathrm{P}=0,0360)$ e ruminação $(\mathrm{r}=0,37, \mathrm{P}=0,0173)$ e inversamente relacionado ao tempo de descanso $(\mathrm{r}=-0,42, \mathrm{P}=0,0059)$. Ambos os fatores climáticos, temperatura e fotoperíodo, influenciaram positivamente os tempos de ingestão e ruminação do gado Jersey confinado.

Observando-se a composição química dos alimentos (Tabela 1), verifica-se maior valor numérico para o teor de fibra da silagem de milho utilizada na estação quente comparada com aquela usada na estação fria, respectivamente, 29,26 e $27,73 \%$ FB. A silagem fornecida foi toda retirada de um mesmo silo, com capacidade inicial de 300 toneladas. Esta diferença no teor de fibra possivelmente foi devida às diferenças na qualidade original da lavoura no mo- 
Tabela 3 - Valores médios do tempo diário de ingestão, ruminação, descanso (min/dia), peso vivo (kg) e produção leiteira (I/dia)

Table 3 - Mean values of daily time spent eating, ruminating, idling (min/day), live weight (Kg) and milk production (L/day)

\begin{tabular}{|c|c|c|c|c|c|c|c|}
\hline & \multicolumn{3}{|c|}{$\begin{array}{l}\text { Período (dias após o parto) } \\
\text { Period (days post partum) }\end{array}$} & \multicolumn{2}{|c|}{$\begin{array}{l}\text { Época } \\
\text { Season }\end{array}$} & $\begin{array}{l}\text { Interação } \\
\text { Interaction }\end{array}$ & \multirow[t]{2}{*}{$\mathrm{CV}(\%)$} \\
\hline & 30 & 60 & 90 & $\begin{array}{l}\text { Fria } \\
\text { Cool }\end{array}$ & $\begin{array}{l}\text { Quente } \\
\text { Warm }\end{array}$ & $\begin{array}{l}\text { Época } \mathrm{x} \text { período } \\
\text { Season } x \text { period }\end{array}$ & \\
\hline \multicolumn{8}{|l|}{ Atividade (min/dia) } \\
\hline \multicolumn{8}{|l|}{ Activity (min/day) } \\
\hline $\begin{array}{l}\text { Ingestão } \\
\text { Eating }\end{array}$ & $371 \mathrm{a}$ & 356 a & $325 \mathrm{~b}$ & $326 \mathrm{~b}$ & $376 \mathrm{a}$ & Não & 12,19 \\
\hline $\begin{array}{l}\text { Ruminação } \\
\text { Ruminating }\end{array}$ & $572 \mathrm{a}$ & $552 \mathrm{a}$ & 539 a & $525 \mathrm{~b}$ & $583 \mathrm{a}$ & Não & 10,66 \\
\hline $\begin{array}{l}\text { Descanso } \\
\text { Idling }\end{array}$ & $494 \mathrm{~b}$ & $528 \mathrm{ab}$ & 565 a & $580 \mathrm{a}$ & $478 \mathrm{~b}$ & Não & 13,73 \\
\hline $\begin{array}{l}\text { Produção de leite (L/dia) } \\
\text { Milk production (L/day) }\end{array}$ & $14,3 \mathrm{a}$ & $12,5 \mathrm{a}$ & 13,8 a & 12,9 a & $14,1 \mathrm{a}$ & Sim & 11,06 \\
\hline $\begin{array}{l}\text { Peso vivo }(\mathrm{kg}) \\
\text { Live weight }(\mathrm{kg})\end{array}$ & 375 a & $378 a b$ & $385 \mathrm{~b}$ & $393 \mathrm{a}$ & 365 a & Não & 18,76 \\
\hline
\end{tabular}

$a, b, c-$ Médias, na linha, seguidas por letras distintas diferem segundo teste Tukey $(P<0,05)$.

$a, b, c-M e a n s$, in a row, followed by different letters are different $(P<.05)$ by Tukey test.

mento da ensilagem. No entanto, esta diferença numérica de 1,5 unidades percentuais no teor de FB é relativamente pequena, quando se compara com outros estudos, onde os autores encontraram diferenças de comportamento de animais alimentados com dietas cujo teor de fibra diferiu de 4 ou mais unidades percentuais (Beauchemin \& Buchanan-Smith, 1989).

O teor de fibra, especialmente o teor de fibra em detergente neutro (FDN) influencia os tempos gastos com a ingestão e ruminação dos alimentos (Colenbrander et al, 1991). Isto ocorre porque a necessidade de mastigação está relacionada com a quantidade de material indigestível ou pouco digestível consumida e com a resistência do material à redução do tamanho de partículas (Fischer, 1996). Alimentos com um alto teor de FDN (Beauchemin \& Buchanan-Smith, 1989, De Boever et al., 1990; Pereira et al., 1998; Oba \& Allen, 2000) ou FDN de baixa degradabilidade (McQueen \& Robinson, 1996) necessitam ser mastigados (e, principalmente, ruminados) por um tempo mais longo.

Desta forma, pode-se inferir que se o teor de fibra da silagem exerceu algum efeito sobre as durações diárias dos tempos de ingestão e ruminação, este efeito foi provavelmente pequeno e de menor importância em relação ao efeito climático.

A produção de leite não diferiu estatisticamente entre as épocas (Tabela 3). No entanto, pode-se observar o maior valor numérico para essa variável na estação quente em relação à estação fria, o que pode ter contribuído para aumentar o tempo de ingestão na época quente em relação à época fria. Vacas de mais alta produção gastaram mais tempo pastando em relação às vacas de menor produção (De Boever et al., 1990; Albright, 1993).

O período da curva de lactação também influenciou o comportamento ingestivo dos animais. $\mathrm{O}$ tempo médio de ingestão foi superior aos 30 e 60 dias pósparto (371 e $356 \mathrm{~min} /$ dia) em relação aos 90 dias após o parto $(325 \mathrm{~min} / \mathrm{dia})(\mathrm{P}=0,0029$ e $\mathrm{P}=0,0109)$. Embora não tenha havido efeito significativo de período sobre o tempo médio diário de ruminação, este seguiu a mesma tendência do tempo diário de ingestão, sendo numericamente maior aos 30 e 60 do que aos 90 dias pós-parto. Embora a produção leiteira não tenha diferido estatisticamente entre os três períodos, particularmente aos 30 dias pós-parto, o tempo de ingestão poderia estar mais relacionado com o maior numérico de produção de leite.

O efeito do estádio de lactação sobre as variáveis comportamentais é devido, principalmente, a mudanças anatômicas, endocrinológicas e metabólicas que ocorrem nos animais durante o período de transição e a fase inicial da lactação, acarretando menor consumo de alimentos. O consumo aumenta gradualmente até atingir o pico em torno de 10 a 14 semanas pósparto (Gottschall, 1999; NRC, 2001).

O consumo voluntário dos animais não foi medido, pois a alimentação foi dada de forma coletiva e os animais experimentais mantidos dentro de seu lote, a fim de medir o comportamento ingestivo sob condições de exploração leiteira, permitindo-se interações entre os animais. No entanto, pode-se inferir que os 
animais utilizados neste experimento apresentaram menor taxa de consumo (kg MS/hora) aos 30 e 60 dias após o parto em relação aos 90 dias pós-parto e uma relação inversa entre consumo voluntário e tempos totais de ingestão e ruminação. Provavelmente, para compensar menor capacidade de consumo nesta fase inicial da lactação, os animais passaram mais tempo ingerindo e ruminando. Segundo Grant \& Albright (1995), vacas leiteiras de alta produção atingem maior consumo de MS através do aumento do tamanho da refeição, com menor tempo gasto ingerindo e ruminando por unidade de MS consumida ou podem modificar seu comportamento ingestivo e/ou a atividade ruminal para manter o consumo (Dado \& Allen, 1995).

O peso vivo dos animais foi semelhante entre as duas épocas (Tabela 3). No entanto, esta variável foi maior aos 90 que aos 30 dias pós-parto $(385 \times 375 \mathrm{~kg}$, $\mathrm{P}=0,0074)$. As vacas apresentaram peso vivo médio ao parto de $395 \mathrm{~kg}$, sendo que até o período próximo ao pico de lactação, perderam $20 \mathrm{~kg}$ peso $(375 \mathrm{~kg})$. Próximo aos 60 dias pós-parto, houve uma estabilização do peso vivo (378 kg), e, a partir dos 90 dias pósparto, pode-se notar uma recuperação do peso dos animais (385 kg). Estes resultados estão de acordo às observações de Davis (1993) e Janssen (1994) sobre a evolução do peso vivo de vacas na fase inicial da lactação. Assim, desde o parto até o final do pico de lactação, a vaca mobiliza abundantemente os depósitos corporais de gordura e pequena proporção de tecido muscular para suprir suas necessidades de energia para a lactação (Davis, 1993; NRC, 2001). De acordo com Janssen (1994), geralmente após os 90 dias pós-parto, a ingestão de MS já é suficiente para suprir as necessidades energéticas.

Segundo alguns autores (De Boever et al., 1990; Deswysen et al., 1993; Fischer, 1996), animais de menor peso vivo podem apresentar menores taxas de mastigação tanto na ingestão, como para a ruminação em relação aqueles de maior peso, o que pode provocar o aumento do tempo total diário dedicado a estas atividades. Entretanto, a diferença de peso vivo dos animais entre os três períodos foi relativamente pequena (Tabela 3) e, provavelmente, exerceu efeito pequeno sobre o tempo de ingestão.

Houve efeito de interação época $x$ período sobre a produção leiteira $(\mathrm{P}=0,0087)$. Nas duas épocas, a produção leiteira foi menor aos 60 dias pós-parto (Tabela 3). Durante a estação quente, houve um incremento maior da produção leiteira dos 60 para os 90 dias após o parto (12,6 x 14,7 L/dia). Durante a estação fria, porém, ocorreu apenas uma pequena diferença na produção leiteira entre estes dois períodos (12,4 x 12,8 L/dia).

Um fator que pode ser levado em consideração é a magnitude da variação no teor de FB do volumoso consumido entre os períodos 2 e 3 da estação quente, respectivamente 31,90 e $24,49 \%$ da MS (Tabela 1), enquanto esta variação não foi tão ampla na estação fria (28,72 x 25,68\% da MS). Contudo, o método de análise da porção fibrosa, com a determinação da fibra bruta pode ter influenciado esses valores, pela variável solubilização da hemicelulose e lignina.

Beauchemin \& Buchanan-Smith (1989) observaram que, à medida que o teor de FDN da dieta aumentou de $26 \%$ para $30 \%$ e $34 \%$, a produção leiteira diminuiu de 20,8 para 19,9 e $19,1 \mathrm{~kg} / \mathrm{dia}$, respectivamente. Esta relação negativa entre o teor de fibra do alimento e a produção leiteira pode ser atribuída à diminuição na capacidade de consumo dos animais (Dado \& Allen, 1995), com conseqüente diminuição do aporte de energia (NRC, 2001) e nutrientes necessários para mantença e produção leiteira, além de uma modificação da fermentação ruminal. Maior teor de fibra provoca aumento da produção de ácido acético e reduz proporcionalmente a produção de ácido propiônico, principal precursor da lactose (Fonseca, 1985). Oba \& Allen (2000) forneceram dietas contendo 29 e $38 \%$ de FDN e verificaram que as vacas que receberam a dieta contendo 29\% de FDN apresentaram maiores consumo voluntário de matéria seca, produção de leite e ganho de peso. McQueen \& Robinson (1996) observaram maior produção de leite em vacas que receberam dieta contendo FDN mais degradável.

O maior valor numérico do teor de FB da silagem possivelmente prejudicou a digestão ruminal, com menor degradação e digestão do volumoso, menor taxa de passagem, menor disponibilidade de nutrientes digeridos para absorção e menor consumo de MS. Como consequiência, ocorreu uma diminuição da produção leiteira aos 60 dias pós-parto. Aos 90 dias pósparto, os teores de FB da ração consumida pelos animais foram mais adequados permitindo, provavelmente, uma digestão mais eficiente no rúmen e, desta forma, a recuperação da produção de leite.

Análises de correlação não permitiram identificar a existência de uma relação entre a produção leiteira e as variáveis comportamentais, isto é, os tempos diários despendidos na ingestão e ruminação, além do tempo gasto descansando por vacas Jersey na fase inicial de lactação. 


\section{Conclusões}

As vacas Jersey em lactação apresentaram maiores tempos diários de ingestão e ruminação durante a época quente comparado à época fria, o que foi relacionado com a maior temperatura ambiente, mas ainda na faixa de conforto térmico dos animais, com o menor peso vivo dos animais e com o maior valor numérico da produção de leite.

As vacas Jersey em lactação apresentaram maior tempo de ingestão e menor tempo de descanso aos 30 e 60 dias pós-parto em relação aos 90 dias pós-parto, o que foi relacionado ao maior valor numérico da produção de leite, à menor capacidade ingestiva dos animais e ao menor peso vivo dos animais.

Não foram verificadas relações entre as variáveis relativas ao comportamento ingestivo dos animais e a sua produção leiteira.

\section{Literatura Citada}

ASSOCIATION OF OFFICIAL ANALITICALCHEMIST-AOAC. Official methods of analysis. Washington, D.C.: 1982. 1141p.

ALBRIGHT, J.L. Nutrition, feeding and calves: feeding behavior of dairy cattle. Journal of Dairy Science, v.76, p.485-498, 1993.

BEAUCHEMIN, K.A.; BUCHANAN-SMITH, J.G. Effects of dietary neutral detergent fiber concentration and supplementary long hay on chewing activities and milk production of dairy cows. Journal of Dairy Science, v.2, n.9, p.2288-2300, 1989.

BEAUCHEMIN, K.A.; RODE, L.M. Nutrition, feeding, and calves: compressed baled alfalfa hay for primiparous and multiparous dairy cows. Journal of Dairy Science, v.77, n.4, p.1003-1012, 1994.

CHASE, L.J.; WANGSNESS, P.J.; BAUMGARDT, B.R. Feeding behavior of steers fed a complete mixed ration. Journal of Dairy Science, v.59, n.11, p.1923-1928, 1976.

COLENDRANDER, V.F.; NOLLER, C.H.; GRANT, R.J. Effect of fiber content and particle size of alfalfa silage on performance and chewing behavior. Journal of Dairy Science, v.74, n.8, p.2681-2690, 1991.

DADO, R.G.; ALLEN, M.S. Nutrition, feeding and calves: Variation in and relationships among feeding, chewing and drinking variables for lactating dairy cows.Journal of Dairy Science, v.77, n.1, p.132-144, 1994.

DADO, R.G.; ALLEN, M.S. Nutrition, feeding, and calves: Intake limitations, feeding behavior, and rumen function of cows challenged with rumen fill from dietary fiber or inert bulk. Journal of Dairy Science, v.78, n. 1, p.118-133, 1995.

DAVIS, C.L.Alimentación de la vaca lechera alta productora. Illinois: Milk Specialties Company, 1993.60p.

DE BOEVER, J.L.; ANDRIES, D.I.; BRABANDER, D.L. et al. Chewing activity of ruminants as a measure of physical structure - A review of factors affecting it. Animal Feed Science and Technology, v.27, p.281-291, 1990.

DESWYSEN, A.G.; ELLIS, W.C.; POND, K.R. Interrelationships among voluntary intake, eating and ruminating behavior and ruminal motility of heifers fed corn silage. Journal of Animal Science, v.64, n.3, p.835-841, 1987.

DESWYSEN, A. G.; DUTILlEUL, P.; GODFRIN, J. P. et al.
Nycterohemeral eating and ruminating patterns in heifers fed grass or corn silage: analysis by finite fourier transform. Journal of Animal Science, v.71, n. 10, p. 2739-2747, 1993.

FISCHER, V. Efeitos do fotoperíodo, da pressão de pastejo e da dieta sobre o comportamento ingestivo de ruminantes. Porto Alegre: Universidade Federal do Rio Grande do Sul, 1996. 243p. Tese (Doutorado em Zootecnia) - Universidade Federal do Rio Grande do Sul, 1996.

FRASER, A.F. Farm animal behavior. Baltimore: Williams \& Wilkins Company, 1973. 196p.

FONSECA, F.A. Fisiologia da lactação. Viçosa, MG: Universidade Federal de Viçosa, 1985. 137p.

GOTTSHALL, C. Alimentação da vaca leiteira visando a máxima produção de leite e desempenho reprodutivo. A hora veterinária, v.9, n.110, p.:66-70, 1999.

GRANT, R.J.; ALBRIGHT, J.L. Feeding behavior and management factors during the transition period in dairy cattle. Journal of Animal Science, v.73, n.9, p.2791-2803, 1995.

HOFFMAN, M.P.; SELF, H.L. Behavioral traits of feedlot steers in Iowa. Journal of Animal Science, v.37, n.6, p.1438-1445, 1973.

JANSSEN, H.P. Alimentação da vaca recém-parida. In: SIMPÓSIO SOBRE PRODUÇÃO DE LEITE, TÉCNICAS E ATERNATIVAS, 1994, Castro. Anais... Castro: Fundação ABC e Cooperativa Central de Laticínios do Paraná, 1994. p.68-74.

Mc QUEEN, R.E.; ROBINSON, P.H. Intake behavior, rumen fermentation and milk production of dairy cows as influenced by dietary levels of fementable neutral detergent fiber.Canadian Journal of Animal Science, v.76, n.3, p.357-365, 1996.

MERTENS, D.R. Regulation of forage intake. In: Forage quality, evaluation and utilization. Madison: American Society of Agronomy, 1994. p.450-493.

NATIONAL RESEARCH COUNCIL - NRC. Nutrients requirements of dairy cattle. 7.ed. Washington, D.C.: National Academy Press, 2001. 408p.

OBA, M.; ALLEN, M.S. Effects of brown midrib3 mutation in corn silage on productivity of dairy cows fed two concentrations of dietary neutral detergent fiber. 1. Feeding behavior and nutrient utilization. Journal of Dairy Science, v.83, n.6, p.1333-1341, 2000.

PEREIRA, E.S.; QUEIROZ, A.C.; NEVES, J.S et al. Níveis de fibra em dietas de novilhas leiteiras: Comportamento ingestivo. In: REUNIÃO ANUAL DA SOCIEDADE BRASILEIRA DE ZOOTECNIA, 35., 1998, Botucatu. Anais... Botucatu: Sociedade Brasileira de Zootecnia, 1998. p.524-526.

PRESCOTT, M.L.; HAVSTAD, K.M.; OLSON-RUTZ, K.M. et al. Grazing behavior of free ranging beef cows to initial and prolonged exposure to fluctuating thermal environments. Applied Animal Behavior Science, v.39, n.2, p.103-113, 1994.

RAY, D.E.; ROUBICEK, C.B. Behavior of feedlot cattle during two seasons. Journal of Animal Science, v.33, n.1, p.72-76, 1971.

SILVA, D.J. Análise de alimentos (Métodos químicos e biológicos). Viçosa, MG: Universidade Federal de Viçosa, 1990. 165p.

TEDESCO, M.J.; GIANELLO, C.; BISSANI, C.A. et al.Análise de solo, plantas e outros materiais. Porto Alegre: Universidade Federal do Rio Grande do Sul, 1995. 174p. (Boletim Técnico, 5)

ZINN, S.; CHAPIN, L.T.; TUCKER, H.A. Does photoperiod and time of feeding affect growth and eating patterns of heifers? Journal of Dairy Science, v.66 (suppl. 1), p.217, 1983.

YOUNG,B.A. The effect of climate uponintake. In:THENUTRITION OFHERBIVORES: SECONDINTERNATIONALSYMPOSIUM ON THE NUTRITION OF HERBIVORS, 1987, Londres. Proceedings... Londres: Academic Press, 1987. p.163-190.

Recebido em: $11 / 06 / 01$ Aceito em: 01/10/02 